\title{
Analisa Penutupan Lahan ( Land Cover ) Kota Palembang Berbasis Sistem Informasi Geografis
}

\author{
lenda Meiriska 1, Leni Novianti ${ }^{2}$, Dewi Irmawati, S 3. \\ 1,2,3 . Jurusan Manajemen Informatika, \\ Politeknik Negeri Sriwijaya \\ Email :1ienda_meiriska_mi@polsri.ac.id
}

\begin{abstract}
This analysis aims to find out the amount of land cover change in Palembang City, where Palembang is one of the cities undergoing land change. The change in land cover is an event of shifting the type of land cover from one species to another followed by increasing and decreasing use over time or changing the function of a land at different times. In Palembang City there are several examples of changing land like paddy fields, and green open spaces. Paddy fields are agricultural farms that are physically flat surfaces, limited by bunds, and can be planted with rice, palawija or other cultivated crops. Most paddy fields are used for cultivation which are classified into 4 types namely technical irrigation, semi technical, simple and rain-fed. Meanwhile, green open spaces are elongated / lane and / or clustered areas, which prefer open, growing plants, either naturally grown and divided into 2 types: natural green open spaces and artificial green open spaces. In this analysis the data used are secondary data satellite map map of 2014 which resulted from Badan Pembangunan dan Pendapatan Daerah (BAPPEDA) Kota Palembang The method used in this analysis is the Natural Break (Jenks) method with emphasis on the color difference of each type of land cover.
\end{abstract}

Keywords: paddy fields, green open space, land cover, natural break (jenks)

\section{Pendahuluan}

Kota Palembang merupakan ibukota dari Provinsi Sumatera Selatan yang sedang bekembang. Secara geografis, Kota Palembang terletak pada koordinat $2^{\circ} 59^{\prime} 27.99^{\prime \prime} \mathrm{LS} 104^{\circ} 45^{\prime} 24.24^{\prime \prime} \mathrm{BT} .24 .24^{\prime \prime} \mathrm{BT}$ dan memiliki luas wilayah $358,55 \mathrm{~km}^{2}$ yang dihuni 1,8 juta orang. Kota Palembang terbagi ke dalam 18 kecamatan dimana kecamatan-kecamatan tersebut meliputi Alang-Alang Lebar, Bukit Kecil, Gandus, Ilir Timur I, Ilir Timur II, Ilir Barat I, Ilir Barat II, Kalidoni, Kemuning, Kertapati, Plaju, Sako, Seberang Ulu I, Seberang Ulu II, Sematang Borang, Sukarame, Jakabaring, Kuto Gawang (Wikipedia,2017).

Kota Palembang adalah salah satu kota yang banyak terjadi pembangunan lahan yang menyebabkan perubahan penutupan lahan suatu kota. Pembangunan yang terjadi pada suatu daerah diikuti oleh perkembangan wilayah tersebut yang menyebabkan perubahan penutupan lahan. Perubahan penutupan lahan adalah bergesernya jenis tutupan lahan dari jenis satu ke jenis lainnya diikuti dengan bertambah dan berkurangnya tipe penggunaan dari waktu ke waktu atau berubahnya fungsi suatu lahan pada waktu yang berbeda (Diyono, 2001). Perubahan penutupan lahan dipengaruhi oleh adanya kemajuan teknologi. Informasi mengenai perubahan tutupan lahan merupakan tutupan lahan merupakan hal yang penting untuk diketahui dalam kegiatan perencanaan. Dalam hal ini informasi yang berkaitan dengan perubahan tutupan lahan digunakan sebagai salah satu data untuk mengetahui karakteristik suatu wilayah khususnya di Kota Palembang.

Tutupan lahan merupakan informasi yang sangat penting dalam sektor pertanian, berupa sawah, lahan kosong, ruang terbuka, kebun, rawa dan tubuh air. Dalam analisa ini informasi data peta tutupan lahan diperoleh melalui teknik penginderaan jauh. Data pengindraan jauh (remote sensing) adalah data dalam bentuk citra dan foto udara atau nonfoto. Penginderaan jauh telah lama menjadi sarana yang penting dan efektif dalam pemantauan tutupan lahan dengan 
kemampuannya menyediakan informasi mengenai keragaman spasial di permukaan bumi dengan cepat, luas, tepat, serta mudah (Hansen et al., 2000; Liu et al., 2003; Thenkabail et al., 2009; Gong et al., 2013). Sumber data penginderaan jauh merupakan faktor penting dalam keberhasilan klasifikasi tutupan lahan (Jia et al., 2014). Data satelit Landsat biasanya digunakan dalam penginderaan jauh untuk klasifikasi tutupan lahan (Gumma et al., 2011; Gong et al., 2013), dengan demikian peta tutupan lahan terbaru dapat diperoleh dengan mudah.

penelitian dengan judul Klasifikasi Tutupan Lahan Menggunakan Citra Landsat 8 Operational Land Image (OLI) di Kabupaten Semedang bertujuan untuk melakukan klasifikasi tutupan lahan di Kabupaten Sumedang menggunakan citra satelit Landsat 8 OLI (Operational Land Imager. Penelitian dilakukan dengan beberapa tahap, yaitu pra-pengolahan citra, pemilihan kombinasi band

terbaik, interpretasi visual citra, membuat penciri kelas, analisis separabilitas, klasifikasi citra, dan uji akurasi. Metode klasifikasi yang digunakan adalah metode maximum likelihood classification (MLC). MLC mempertimbangkan faktor prior probability yaitu peluang dari suatu piksel untuk dikelaskan ke dalam kelas atau kategori tertentu. Hasil klasifikasi citra Landsat 8 OLI di Kabupaten Sumedang menghasilkan 10 kelas tutupan lahan yaitu lahan terbangun, sawah menjelang panen, sawah baru tanam, semak belukar, hutan tutupan padat, hutan tutupan sedang, hutan campuran, kebun campuran, tanah terbuka dan badan air.

( Putiksari dkk, 2014) menjelaskan bahwa pembukaan lahan sebagai salah satu kegiatan utama dalam eksplorasi panas bumi dan aktivitas manusia menyebabkan lebih banyak deforestasi di Cagar Alam Kamojang dan mengganggu peran hutan sebagai penyimpan jasa lingkungan. Tujuan dari penelitian ini adalah: 1) untuk mengukur perubahan tutupan lahan dan menentukan status hutan Kamojang cagar alam dan 2) untuk mengidentifikasi faktorfaktor sosial-ekonomi yang menyebabkan deforestasi. Laporan analisis dari citra landsat menunjukkan kepada kita jenis tutupan lahan didominasi oleh hutan sekitar
4.231,26 ha dengan prosentase tutupan hutan sekitar 51,17\%. Dengan hasil itu, Kamojang cagar alam telah disebut sebagai status terganggu. Dalam kasus lain, faktor sosio-ekonomi yang menyebabkan deforestasi yang benar-benar signifikan untuk gaji dan status kepemilikan lahan.

Penelitian Analisis Penggunaan Lahan dan Penutupan Lahan juga sudah dilakukan oleh

(Wahyuni dkk, 2014) dengan studi kasus di daerah Kabupaten Dairi Provinsi Sumatera Utara dengan menggunakan satelit Citra Landsat TM 7.

\section{METODE PENELITIAN}

\subsection{Waktu dan Tempat}

Penelitian ini dilakukan pada

Kotamadya Palembang dan menggunakan labarotarium dijurusan Manajemen Informatika Politeknik Negeri Sriwijaya Palembang.

\subsection{Bahan - bahan yang digunakan :}

a. Data primer maupun skunder yang berhubungan dengan kotamadya Palembang.

b. Peta

c. Buku-buku dan jurnal-jurnal penelitian yang teliti.

berhubungan dengan studi kasus yang

d. Peta satelit Kota Palembang 2014.

\subsection{Peralatan yang digunakan:}

2.3.1 Perangkat Keras (hardware); a.Laptop dengan spesifikasi :

T6600

$$
\text { a.1.Intel Core }{ }^{\mathrm{TM}} 2 \text { Dou processor }
$$

$$
\text { a.2.Intel GMA 4500MHD, } 160 \text { GB }
$$

HDD

$$
\begin{aligned}
& \text { a.3.GB Memory } \\
& \text { a.4.14.0" HD LED LCD. }
\end{aligned}
$$

\subsubsection{Perangkat Lunak (software)}

a. Microsoft Windows Embedded

b. Argis 10.1 


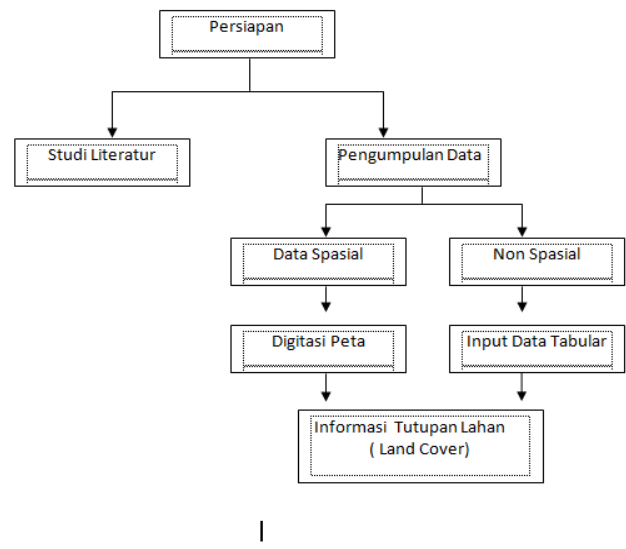

Gambar 1. Diagram Alur Kerangka Pemikiran

\section{HASIL DAN PEMBAHASAN}

Metode penelitian yang digunakan adalah model Prototyping .

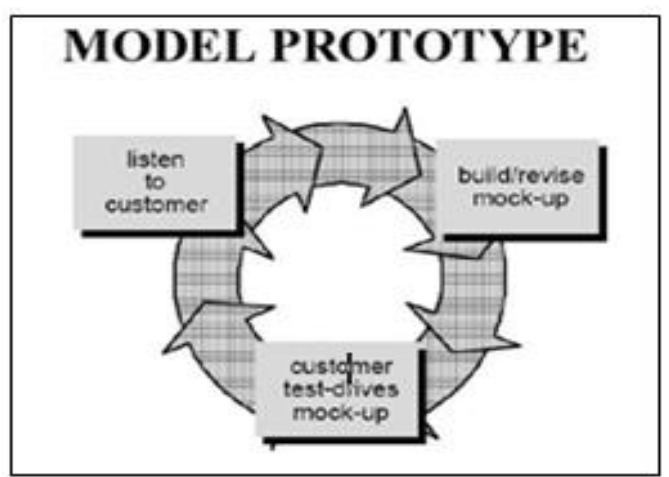

Gambar.2 Model Prototype

\section{Analisa Kebutuhan}

1) Identifikasi Masalah maka dapat diidentifikasikan beberapa permasalahan sebagai berikut :

a.Jenis-jenis perubahan penutupan lahan.

b.Titik daerah perubahan penutupan lahan.

2) Analisa Sistem

2.1 Pengambilan data secara langsung melalui Bappeda dan melalui data skunder yaitu dengan literatur atau browsing.

2.2 Analisa ini mecakup Kota Palembang wilayah 3 dengan analisa Ruang Terbuka Hijau dan Sawah.
3) Kebutuhan Data maka dapat diidentifikasikan beberapa permasalahan sebagai berikut :
a. Jenis-jenis perubahan penutupan lahan.
b. Titik daerah perubahan penutupan lahan.

\section{Design Sistem}

Desain yang dimaksud bukan hanya tampilan atau interface saja melainkan terdiri juga dari desain sistem yang meliputi : alur kerja sistem, cara pengoperasian sistem, hasil keluaran (output) sistem dengan menggunakan metode - metode tampilan sistem dan lain - lain yang telah disesuaikan dengan analisis kebutuhan.

Pengolahan Data Sistem Informasi Geografis (SIG)

a. Data Spasial

Data spasial adalah data yang memiliki keruangan dimana berbagai data atribut terletak dalam berbagai unit spasial. Data spasial yang diunakan dalam analilsa ini berbentuk poligon (polygon) karena dalam peta ini yang dianalisa berbentuk wilayah.

b.Data Non-spasial (Atribut).

Data atribut adalah data yang memberi keterangan atau mendeskripsikan data spasial (keruangan). Dalam hal ini data nonspasial yang digunakan adalah data mengenai luas wilayah ruang terbuka hijau dan sawah di Kota Palembang.

\section{c.Peta Digitasi Penutupan Lahan}

(Land Cover).

Pengelolaan data spasial merupakan hal yang penting dalam pengembangan daerah perkotaan. SIG secara teknis mengorganisasikan dan memanfaatkan data spasial. Dunia nyata dalam SIG dijabarkan dalam data peta digital yang menggambarkan posisi dari ruang dan klasifikasi, atribut data, dan hubungan antar item data. Berikut adalah peta citra satelit tahun 2010 sebelum didigitasi, peta citra satelit tahun 2010 setelah didigitasi serta peta hasil output beserta legenda: 


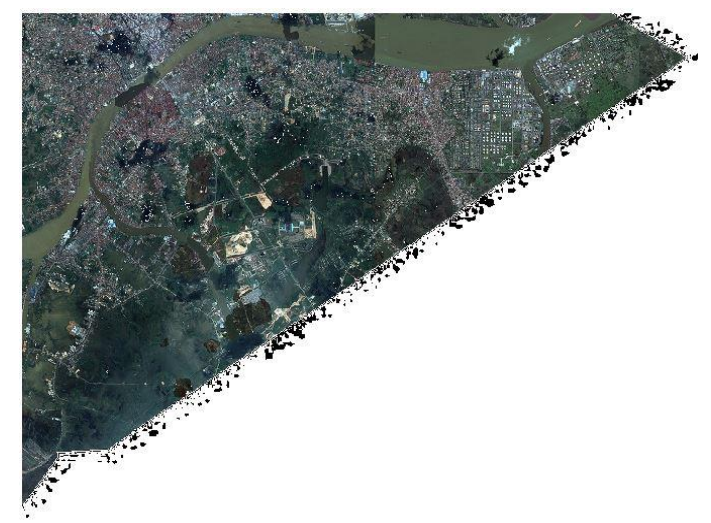

Gambar 2. Peta Citra Satelit 2014 Kota Palembang

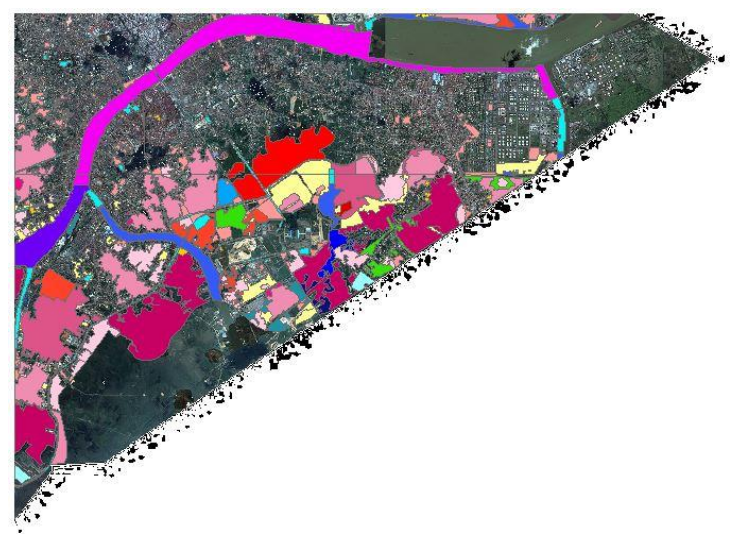

Gambar 3. Peta Citra Satelit 2014 Kota Palembang Setelah Didigitasi

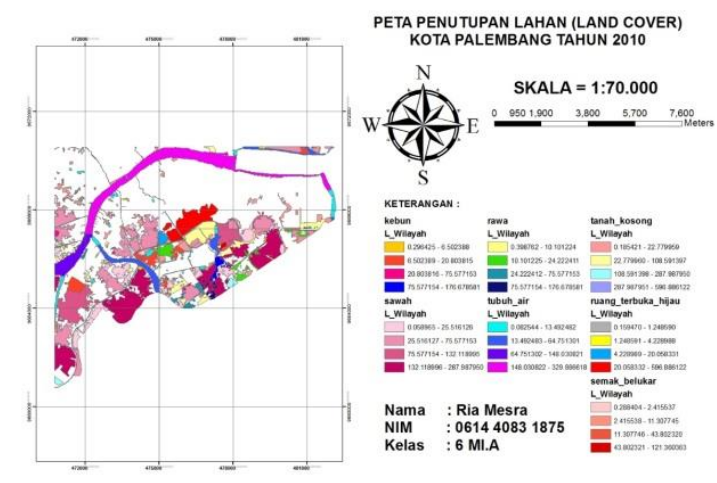

Gambar 4. Peta Penutupan Lahan (Land Cover)
Dari gambar diatas, terdapat 7 jenis dalam penutupan lahan (land cover) yang terdiri dari kebun, sawah, tanah kosong, tubuh air, semak belukar, tanah kosong dan ruang terbuka hijau. Dari hasil digitasi tersebut, terdapat dua jenis penutupan lahan yang akan dianalisa, yaitu sawah dan ruang terbuka hijau dengan skala digitasi 1:1.000 dan skala pengimplementasi 1:70.000.

Sawah adalah lahan usaha pertanian yang secara fisik berpermukaan rata, dibatasi oleh pematang, serta dapat ditanami padi, palawija atau tanaman budidaya lainnya. Kebanyakan sawah digunakan untuk bercocok tanam padi yang diklasifikasikan menjadi 4 jenis yaitu irigasi teknis, semi teknis, sederhana dan tadah hujan. Sementara untuk ruang terbuka hijau adalah area memanjang/jalur dan/atau mengelompok, yang penggunaannya lebih bersifat terbuka, tempat tumbuh tanaman, baik yang tumbuh secara alamiah maupun yang sengaja ditanam yang diklasifikasikan menjadi 2 jenis yaitu ruang terbuka hijau alami dan ruang terbuka hijau buatan.

Dari masing-masing jenis tesebut, memiliki sampling berjumlah 10.000 dengan statistik klasifikasi sebagai berikut :

\begin{tabular}{|c|c|}
\hline Count & 82 \\
\hline Minimum & 0.058965 \\
\hline Maximum & 287.987950 \\
\hline Sum & 4168.115648 \\
\hline Mean & 50.830679 \\
\hline Median & 22.517566 \\
\hline $\begin{array}{l}\text { Standard } \\
\text { Deviation }\end{array}$ & 67.780440 \\
\hline Break Values & $\begin{array}{l}25.516126 \\
75.577153 \\
132.118995 \\
287.987950\end{array}$ \\
\hline
\end{tabular}

b. Ruang Terbuka Hijau

\begin{tabular}{|l|l|}
\hline Count & 10 \\
\hline Minimum & 0.159470 \\
\hline Maximum & 596.886122 \\
\hline Sum & 3010.872321 \\
\hline Mean & 301.087232 \\
\hline Median & 308.472227 \\
\hline $\begin{array}{l}\text { Standard } \\
\text { Deviation }\end{array}$ & 295.846643 \\
\hline Break Values & 1.248590 \\
& 4.228988 \\
& 20.058331 \\
\hline
\end{tabular}




\subsection{2}

Analisa ini menggunakan metode Natural Break (Jenks) dengan menitik beratkan pada perbedaan warna dari masing-masing jenis tutupan lahan. Untuk sawah memiliki jumlah lahan terbesar yaitu 132.118996 - 289.987950 meter dan ruang terbuka hijau sebesar $20.058332-596.886122$ meter.

\section{KESIMPULAN DAN SARAN}

\subsection{Kesimpulan}

Dari analisa diatas dapat disimpulkan bahwa sawah dan ruang terbuka hijau merupakan bagian dari tutupan lahan. Dimana untuk sawah diklasifikasikan menjadi 4 jenis dengan range wilayah sebagai berikut :
a. Irigasi Teknis
b. Semi Teknis.
c. Sederhana.
d. Tadah Hujan.

Sementara untuk ruang terbuka hijau, diklasifikasi menjadi 2 jenis yaitu ruang terbuka hijau alami dan ruang terbuka hijau buatan dengan kisaran wilayah :

a. Ruang Terbuka Hijau Alami.

b. Ruang Terbuka Hijau Buatan.

\subsection{Saran}

Saran dari analisa ini yaitu agar dapat diperluas lagi informasi mengenai penutupan lahan (land cover) di Kota Palembang dimana informasi tersebut dapat berupa data-data yang valid dan reliable (dapat dipercaya).

\section{DAFTAR PUSTAKA}

Dhani Susanto,Aditya, etc 2014. Analisis

Tingkat Rawan Kekeringan Lahan Sawah Dengan Pemanfaatan Penginderaan Jauh dan Sistem Informasi Geografis di Kabupaten Sragen. Mahasiswa Fakultas Geografi Universitas Muhammadiyah Surakarta, E : 100130042.

Mulya Sampurno ,Rizky, etc 2016. Klasifikasi Tutupan Lahan Menggunakan Citra Landsat 8 Operational Land Imager (OLI) di Kabupaten Sumedang. Jurnal Teknotan Vol.10 No.2, P-ISSN : 1978-1067 ; EISSN : 2528-6285.

Sri Wahyuni, Hardy Guchi*, Benny Hidayat . Analisis Perubahan Penggunaan Lahan dan Penutupan Lahan Tahun 2003 dan 2013 di

Kabupaten Dairi. Jurnal Online

Agroekoteknologi . Vol.2, No.4 : 1310-

1315 , September 2014. ISSN No. 2337 6597.

https://kawasankonservasi.wordpress.com/201 4/11/15/memaknai-tutupan-lahan/ (Diakses tanggal 12 Juni 2019)

http://www.landasanteori.com/2019/10/penger tian-sistem-informasi-geografis.html (Diakses tanggal 12 Juni 2019)

http://www.penataanruang.com/ruang-terbukahijau.html (Diakses tanggal 12 Juni 2019)

http://ilmudasartani.blogspot.co.id/2019/05/pe ngertian-sawah.html (Diakses tanggal 12 Juni 2010)

http://bentangalamhutantropis.fkt.ugm.ac.id/arc-gis/ (Diakses tanggal 12 Juni 2019)

https://www.academia.edu/12100468/Lapres Modul_1_ArcGIS (Diakses tanggal 12 Juni 2019)

http://repository.ipb.ac.id/bitstream/handle/123 456789/2341/A08mei.pdf.txt;jsessionid=112D 644CDB5E0F5489C9B79261F0F234?sequenc $\underline{\mathrm{e}=5 \text { (Diakses tanggal } 12 \text { Juni 2019) }}$ 